\title{
Effect of anthropogenic heat sources in the shallow subsurface at city-scale
}

\author{
Monika J. Kreitmair ${ }^{1 *}$, Nikolas Makasis ${ }^{1}$, Asal Bidarmaghz², Ricky L. Terrington ${ }^{3}$, Gareth J. Farr ${ }^{4}$, Johanna M. \\ Scheidegger ${ }^{3}$, Ruchi Choudhary ${ }^{1}$ \\ ${ }^{1}$ Engineering Department, University of Cambridge, Trumpington Street, Cambridge CB2 1PZ, United Kingdom \\ ${ }^{2}$ School of Civil and Environmental Engineering, University of New South Wales, Sydney, NSW 2052 Australia \\ ${ }^{3}$ British Geological Survey, Keyworth, Nottingham NG12 5GG, UK \\ ${ }^{4}$ British Geological Survey, Cardiff University, Park Place, CF10 3AT
}

\begin{abstract}
Rapid rates of urbanisation are placing growing demands on cities for accommodation and transportation, with increasing numbers of basements and tunnel networks being built to meet these rising demands. Such subsurface structures constitute continuous heat sources and sinks, particularly if maintained at comfortable temperatures. At the city-scale, there is limited understanding of the effect of heat exchange of underground infrastructures with their environments, in part due to limited availability of long-term underground temperature data. The effects of underground temperature changes due anthropogenic heat fluxes can be significant, impacting ventilation and cooling costs of underground spaces, efficiency of geoenergy systems, quality and quantity of groundwater flow, and the health and maintenance of underground structures. In this paper we explore the impact of anthropogenic subsurface structures on the thermal climate of the shallow subsurface by developing a heat transfer model of the city of Cardiff, UK, utilising a recently developed semi-3D modelling approach.
\end{abstract}

\section{Introduction}

Growing population sizes and the resulting requirements on infrastructures within cities are creating an increased demand on the shallow subsurface for competing uses i.e. for energy applications, living spaces, and commercial structures. These uses inevitably generate and consume heat from the surrounding ground. At the local scale, underground temperature increases due anthropogenic heat fluxes are well-established. However, less understanding exists of the effects of heat exchange between underground infrastructures and their environment at the city-scale, in part due to limited availability of long-term temperature data. The effects can be significant, with ground temperature anomalies propagating as far as $130 \mathrm{~m}$ below ground level in the city of Winnipeg, Canada [1]. Bidarmaghz et al. [2] showed increases in ground temperatures in the range of 1 to $5.5{ }^{\circ} \mathrm{C}$ within the Royal Borough of Kensington and Chelsea, London due to the presence of heated basements. Changes in underground temperatures can impact ventilation and cooling costs of underground spaces, efficiency of geo-energy systems, quality and quantity of groundwater flow, and the health and maintenance of underground structures. Rivera et al. [3] showed that raised urban ground temperatures in central Europe could reduce the length required for a given heating power supply by $4 \mathrm{~m}$. In some urban areas, the geothermal potential may even exceed the residential thermal demand [4].

A significant contributor to the spatial extent and magnitude of increased underground temperatures caused by heated infrastructure is the geological character of the surrounding environment as well as the density of the heat flux generating infrastructures. In the study presented in this paper, the geology of the citycentre of Cardiff, UK is combined with an accurate representation of buildings which have heated basements. This builds on previous work by Bidarmaghz et al. [2,5] by accounting for more refined geological variation in and a greater realism in the building distribution. A numerical model is created using the finite element solver COMSOL Multiphysics ${ }^{\circledR}[6]$ where coupled heat transfer in porous media and fluid flow through the media is considered. Resulting ground temperatures were compared with temperature time series measured at different locations within the modelled domain.

This paper is structured as follows. In section 2 the methodology used is introduced, presenting the study region, the hydrogeological conditions and heat sources within the region, and the physics underlying the numerical modelling. In section 3 , results obtained from the model are presented and compared to data collected within the modelled region. In section 4, the results are discussed and conclusions drawn as to avenues available for future work.

\footnotetext{
* Corresponding author: mk2040@cam.ac.uk
} 


\section{Methodology}

The region chosen for the model study is the Cardiff city centre. It was selected due to a considerable number of temperature measurements being available within this area over the course of several years, courtesy of the British Geological Survey (BGS). Measurements were taken in boreholes throughout the city, measuring at various depths (between $1.5 \mathrm{~m}$ and $18.9 \mathrm{~m}$ below ground level) in the shallow subsurface. The modelled area was selected in an attempt to balance available data and computational expense, while retaining a relevant mixture of basement types within the model domain. It consists of a rectangle of about $3.5 \mathrm{~km}^{2}$ in the Southeast part of the city, shown in Figure 1.

\subsection{Hydrogeology of study area}

The city of Cardiff is located in the Southwest of the United Kingdom, on the coast of the Bristol Channel (see inset in Figure 1). The environment of the city is built predominantly on glaciofluvial sediment deposits, consisting chiefly of permeable sand and gravels. Lithologic characteristics of the modelled domain were determined from data provided by the BGS, of the lithologic classification within a $50 \mathrm{~m} \times 50 \mathrm{~m}$ grid, as shown in Figure 2 for layers at $z=\{0,-10,-15\} \mathrm{m}$ below ground level. The raster grid was used to generate a linearly interpolated function of the thermal and hydraulic parameters to be used by the finite element solver. Values of these parameters are given in Table 1. Where data were unavailable for the lithology specific to the area, generic values were used.

The topmost layer of the area studied consists predominantly of made ground (man-made deposits on the natural ground surface [7]) interspersed with glaciofluvial sand and gravel, tidal flat deposits, and

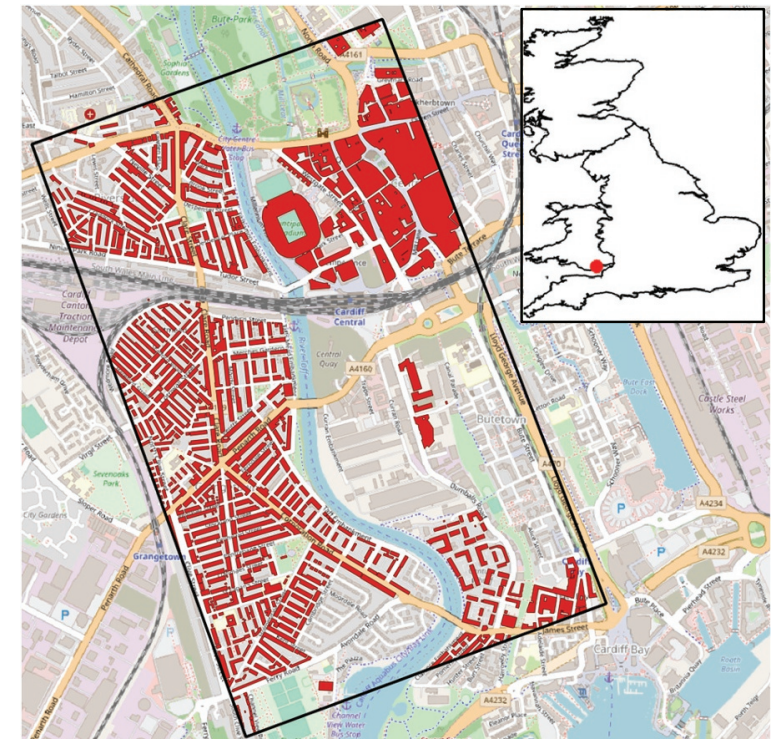

Fig. 1. Location of study area (inset) and outlines of buildings with heated basements [9].

alluvium being found in the northern region of the study area. Deeper below ground, the made ground gives way to increasing amounts of glaciofluvial sediment and tidal flat deposits. This is underlain by bedrock which consists of low permeability Triassic Mercia Mudstone, constituting the base of the city's aquifer, which begins to permeate more and more of the modelled region. Below a depth of approximately $z=-25 \mathrm{~m}$, the domain consists almost exclusively of the Mercia Mudstone bedrock.

A hydraulic head distribution was provided through a detailed hydraulic model produced by BGS, shown in Figure 3. In several regions of the city the groundwater levels are artificially controlled to mitigate the rise in groundwater levels in particular areas with a large
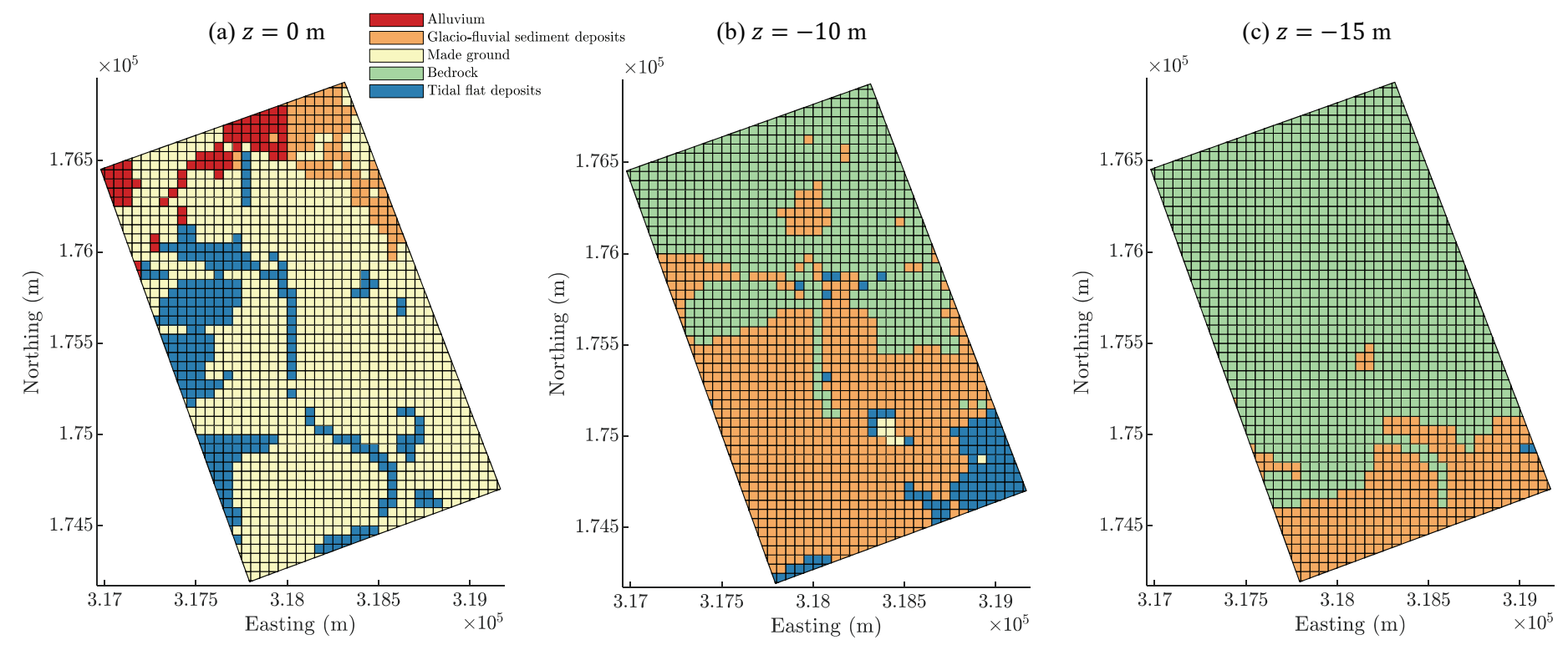

Fig. 2. Geographic material applied in a 50x50 m grid at depths of (a) $0 \mathrm{~m}$, (b) $10 \mathrm{~m}$, and (c) $15 \mathrm{~m}$ below ground level, showing the variation of the geological material with depth. 
Table 1. Thermal and hydraulic properties of geological materials present in the modelled domain. Thermal diffusivity was calculated according to $\alpha=\lambda /\left(\rho C_{p}\right)$.

\begin{tabular}{ccccccc}
\hline Geology & $\begin{array}{c}\text { Thermal } \\
\text { conductivity, } \lambda \\
{\left[\mathrm{W}(\mathrm{mK})^{-1}\right]}\end{array}$ & $\begin{array}{c}\text { Density, } \rho \\
{\left[\mathrm{Mg} \mathrm{m}^{-3}\right]}\end{array}$ & $\begin{array}{c}\text { Specific heat } \\
\text { capacity, } C_{p} \\
{\left[\mathrm{~kJ}(\mathrm{~kg} \mathrm{~K})^{-1}\right]}\end{array}$ & $\begin{array}{c}\text { Porosity, } \\
\varepsilon \\
{[-]}\end{array}$ & $\begin{array}{c}\text { Hydraulic } \\
\text { conductivity, } k_{h} \\
{\left[\mathrm{~m} \mathrm{~s}^{-1}\right]}\end{array}$ & $\begin{array}{c}\text { Thermal } \\
\text { diffusivity, } \alpha \\
{\left[\mathrm{m}^{2} \mathrm{~s}^{-1}\right]}\end{array}$ \\
\hline Glaciofluvial sediment deposit & $1.80[10]$ & 2.00 & $1.75[13]$ & $0.2[14]$ & $5.79 \times 10^{-4}[15]$ & $5.15 \times 10^{-7}$ \\
Made ground & $0.5[10]$ & 2.00 & 1.27 & 0.5 & $2.31 \times 10^{-5}[16]$ & $1.97 \times 10^{-7}$ \\
Bedrock (Mercia mudstone) & $1.08[11]$ & $2.01[12]$ & 1.10 & $0.3[12]$ & $3.66 \times 10^{-11}[17]$ & $4.86 \times 10^{-7}$ \\
Alluvium \& tidal flat deposits & $1.11[11]$ & $1.67[11]$ & 1.18 & 0.5 & $2.01 \times 10^{-10}[11]$ & $5.64 \times 10^{-7}$ \\
\hline
\end{tabular}

number of basements [8]. The difference in hydraulic head within the region is small, giving a shallow hydraulic head gradient of approximately $1.6 \times 10^{-3}$.

\subsection{Heat sources}

For the purpose of this study, solely the anthropogenic thermal fluxes from basements were considered. In reality other heat sources exist, e.g. sewage networks and ground source heat pumps. Furthermore, variation in surface cover was not considered. Ground temperature is greatly affected by surface cover which affects the heat flux boundary condition at the surface of the modelled domain.

Basement geometries were obtained from the Ordnance Survey Agency [9]. Footprints for all the buildings within the domain were reviewed according to their attributes (resident use vs. industrial use, year of construction, etc.) to develop an understanding of the likelihood of each building having a basement. This was combined with local knowledge in order to allocate basements (Figure 1). Basements were assumed to penetrate the ground a total depth of $3 \mathrm{~m}$ and walls were assumed to consist of waterproof concrete with a

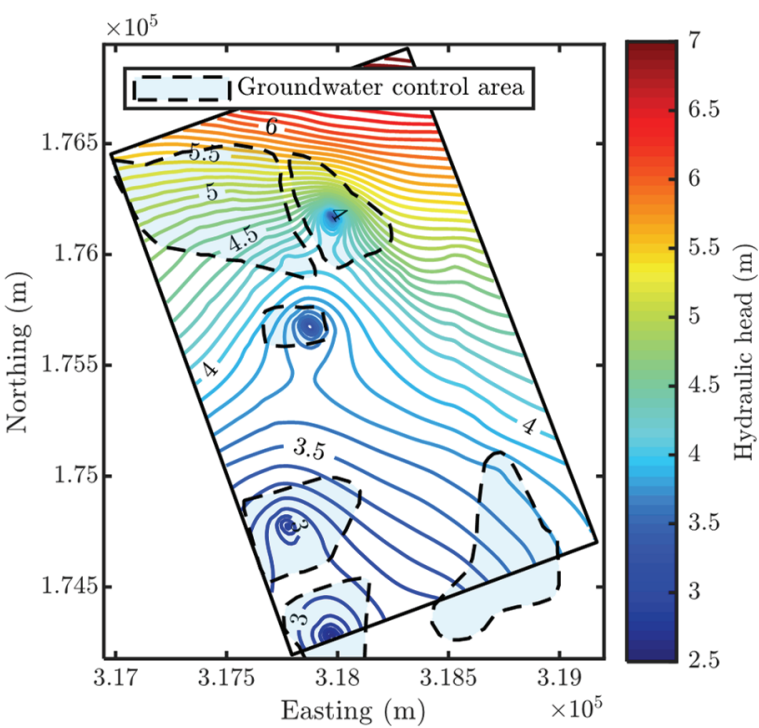

Fig. 3. Hydraulic head distribution within study domain. Groundwater levels are pumped within dashed regions (copyright BGS, UKRI) thermal conductivity of $\lambda_{\text {wall }}=1.2 \mathrm{~W}(\mathrm{mK})^{-1}$. In the model, the basements were brought to $T_{\text {room }}=18{ }^{\circ} \mathrm{C}$ over a period of 30 days using a sigmoid function and then maintained at $18{ }^{\circ} \mathrm{C}$ to simulate heating to comfortable levels.

\subsection{Undisturbed ground temperature}

Taking into account the seasonal temperature fluctuation in the air, the undisturbed ground temperature as a function of time and depth, as well as the temperature applied at the top of the model, is given by a combination of models presented by Beardsmore and Cull [18] and Baggs [19] as

$$
\begin{gathered}
\mathrm{T}_{\mathrm{g}}(\mathrm{z}, \mathrm{t})=\mathrm{T}_{0, \mathrm{~g}}-1.07 k_{v} \mathrm{~T}_{a m p} \mathrm{e}^{-\epsilon \mathrm{z}} \cos [\omega(t- \\
\left.\left.t_{0}\right)-\epsilon z\right],
\end{gathered}
$$

where $\mathrm{T}_{0, \mathrm{~g}}$ is the mean annual ground temperature, $\mathrm{T}_{a m p}$ the seasonal heating cycle amplitude, $\omega=2 \pi / P$ is the angular frequency of the heating cycle with period $P=$ 365 days, $\epsilon=\sqrt{\pi /(P \alpha)}, \alpha$ is the thermal diffusivity of the ground, $k_{v}$ is the vegetation coefficient, and $t_{0}$ is the day of coldest temperature after January $1^{\text {st }}$. From deep borehole measurements [20], the mean annual ground temperature was determined to be $\mathrm{T}_{0, \mathrm{~g}}=12.9^{\circ} \mathrm{C}$. Weather data from the Cardiff area [21] was used to determine values of $\mathrm{T}_{a m p}=6.5^{\circ} \mathrm{C}$ and $t_{0}=26$ days.

\subsection{Numerical model setup}

The numerical semi-3D approach used in this paper was developed by Bidarmaghz et al. [5], whereby the 3D geometry of the domain is sub-divided into 2D horizontal planes. Within each plane, heat flow is modelled through conduction in porous media and convection via groundwater flow. Planes are thermally coupled to their nearest neighbours by out-of-plane heat fluxes. The equations governing temperature of the ground $T_{m}$ within a plane due to both conduction and convection due to fluid (i.e. groundwater) flow are that of convective and conductive heat transfer [22],

$$
\left(\rho_{f} C_{p, f}\right) \boldsymbol{v}_{f} \nabla T_{m}+\nabla \cdot \boldsymbol{q}=\mathbf{0},
$$

where $\rho_{f}$ is groundwater density, $C_{p, f}$ is the specific heat capacity of the fluid, $v_{f}$ is the Darcy velocity of the fluid, and $\boldsymbol{q}$ is the heat flux. The heat flux is related to 
the gradient of the ground temperature field via the effective thermal conductivity, i.e.

$$
\boldsymbol{q}=\lambda_{\text {eff }} \nabla T_{m},
$$

where the effective thermal conductivity is given by $\lambda_{e f f}=(1-\varepsilon) \lambda_{m}+\varepsilon \lambda_{f}$, and $\lambda_{m}$ and $\lambda_{f}$ are the thermal conductivity of the porous solid and of the groundwater, respectively, and $\varepsilon$ is the porosity of the ground.

Within each layer, the single-phase fluid flow through a porous medium is modelled using Darcy's Law, which relates the Darcy velocity field of the fluid to the total head gradient $\nabla Z$ and the dynamic viscosity of the fluid $\mu_{f}$ and the properties of the porous medium,

$$
\boldsymbol{v}_{f}=-\frac{K}{\mu_{f}}\left(\nabla p_{f}-\rho_{f} \boldsymbol{g} \nabla Z\right),
$$

where the permeability $K$ of the material is related to the hydraulic conductivity $k_{h}$ by $K / \mu_{f}=k_{h} /\left(\rho_{f} \boldsymbol{g}\right)$. Combination of equation (4) and the continuity equation, $\nabla \cdot\left(\rho_{f} \boldsymbol{v}_{f}\right)=0$, gives the generalised governing equation, i.e.

$$
\nabla \cdot \rho_{f}\left[-\frac{K}{\mu_{f}}\left(\nabla p_{f}-\rho_{f} \boldsymbol{g} \nabla Z\right)\right]=0 .
$$

Equations (4) and (5) are solved for the Darcy velocity and the fluid pressure and coupled to (2) via this velocity.

Inter-plane heat transfer is taken into account by setting up out-of-plane heat fluxes. Defining the distance between the planes as $\mathrm{d} z$, equation (2) is altered to take into account sources of heat flux from planes above and below through the inclusion of source terms:

$$
\mathrm{d} z\left(\rho_{f} C_{p, f}\right) \boldsymbol{v}_{f} \cdot \nabla T_{m}+\nabla \cdot \boldsymbol{q}=q_{0, u p}+q_{0, \text { down }},
$$

where the upside and downside out-of-plane heat fluxes, respectively, are given by

$$
q_{0, u p}=\lambda_{e f f}\left(T_{n-1}-T_{n}\right) / \mathrm{d} z,
$$

and

$$
q_{0, \text { down }}=\lambda_{\text {eff }}\left(T_{n+1}-T_{n}\right) / \mathrm{d} z .
$$

In summary, the initial and boundary conditions applied to the model are:

- Hydraulic head values are assigned throughout the domain using the distribution show in Figure 3;

- Basements constituting heat sources, as shown in Figure 1, were maintained at $18{ }^{\circ} \mathrm{C}$;

- An initial temperature profile given by (1) at $t=0$, and pressure of 1 atmosphere were applied throughout the modelled domain;

- At the uppermost plane, a time-varying heat flux into the layer from above is applied by (7) with $T_{n-1}$ set to the value given by (1);

- At the bottommost plane, a heat flux into the layer from below is determined by (8) with $T_{n+1}=\mathrm{T}_{0, \mathrm{~g}}=$ $12.9^{\circ} \mathrm{C}$

The model was allowed a run-up period of 10 years and subsequently run for an additional 10 years to generate model outputs to be compared with measured data.

\section{Results}

Figure 5 shows model output of the temperature distribution within Cardiff at a depth of $7 \mathrm{~m}$ below ground level at the end of November. The footprints of the heated basements are clearly visible at this depth as regions of elevated temperature. The shape of these regions is only slightly altered from that at ground level, being projected down through the layers. The shallow hydraulic gradient in the area means there is only little convective heat transfer and footprints of the basements are only slightly smeared out as the elevated temperature of the basements permeates down.

Figure 6 shows four borehole locations at which temperature measurements were taken within the modelled domain. These locations were chosen to explore the ability of the model to capture the temperature at points of different depths and proximities to high-density areas of heated basements. Two are situation below an area of basements west of the river (boreholes CS229 and CS285 at depths of 7.0 and 3.2 metres below ground level respectively). The other two are located far from heated basements, east of the river (boreholes CS283 and CS318 at 7.7 and 3.0 metres below ground level, respectively).

Measured and modelled ground temperature timeseries at the four other locations are shown in Figure 7. Phase and frequency of the measured data is wellcaptured by the seasonally varying temperature applied as boundary condition to the model. However, the amplitude is significantly under-estimated at all locations. This further indicates that the vertical heat flux is inadequately captured by the model. The decay of temperature amplitude with depth, both measured and modelled, appears it be unaffected by proximity to basements as the fluctuations in Figures $7 \mathrm{~b}$ and $7 \mathrm{~d}$ and in Figures $7 \mathrm{a}$ and $7 \mathrm{c}$ are of similar amplitude. The mean temperature is measured at location CS229 (Figure 7b) is found to be approximately 1 degree higher than that at CS283 (Figure 7d) despite the two locations having very similar vertical geographic profiles. The same

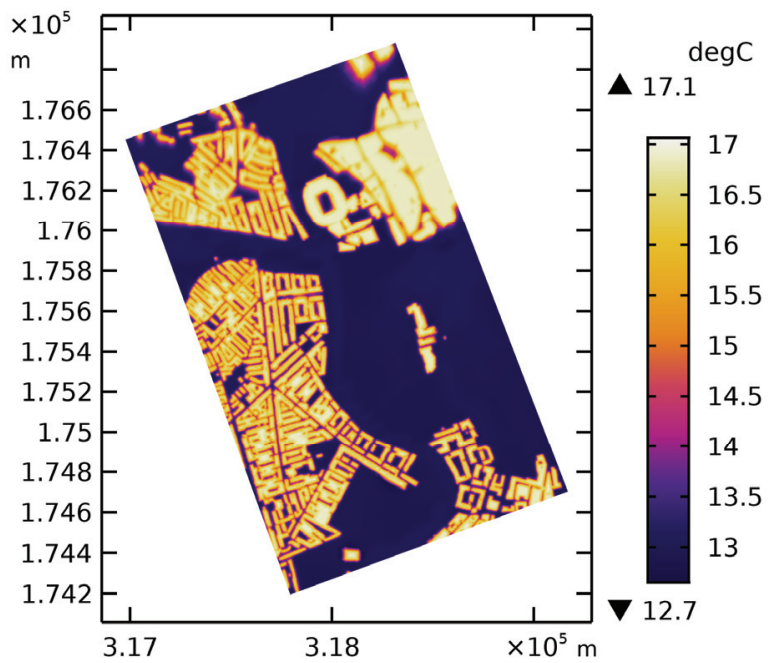

Fig. 5. Temperature distribution at $z=-7 \mathrm{~m}$ in November. 


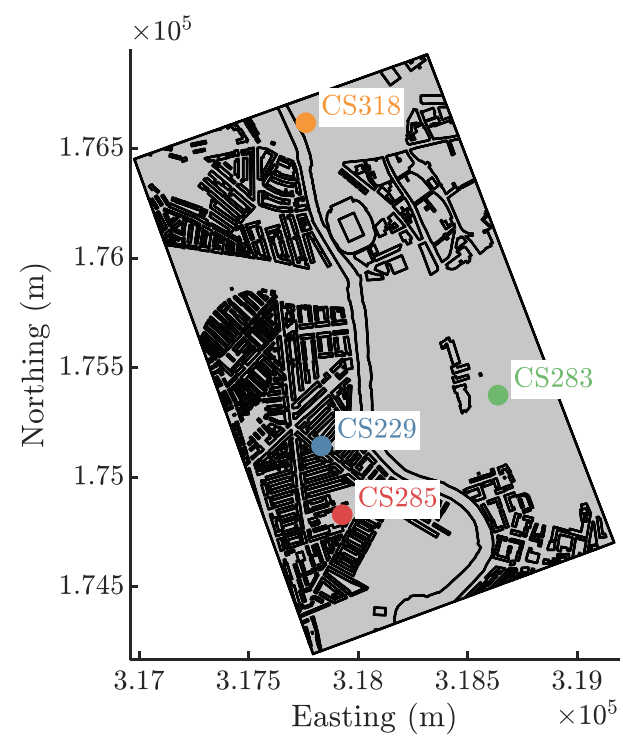

Fig. 6. Location and names of boreholes.

discrepancy is not observed between Figures $7 \mathrm{a}$ and $7 \mathrm{c}$, despite significant differences in profiles. This indicates that the basement temperature, set at $T_{\text {room }}=18{ }^{\circ} \mathrm{C}$ for all basements, is likely too high, as only the point exhibiting this discrepancy is located below a region with very high basement density.

(a) CS285, close to basements, $z=-3.2 \mathrm{~m}$

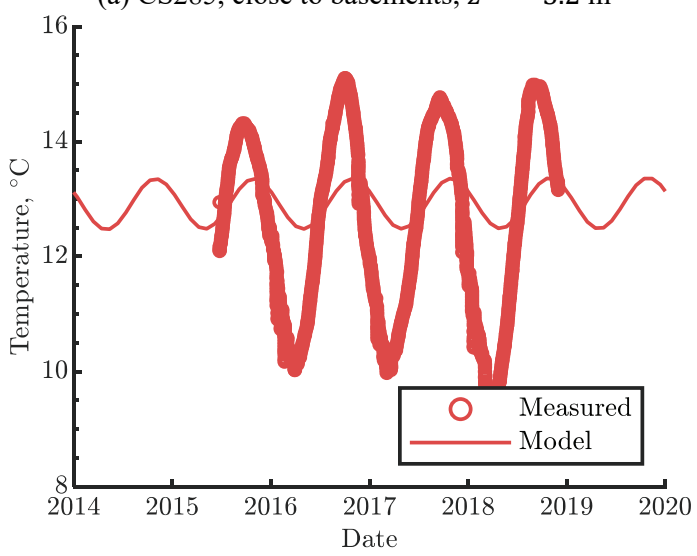

(c) CS318, far from basements $z=-3.0 \mathrm{~m}$

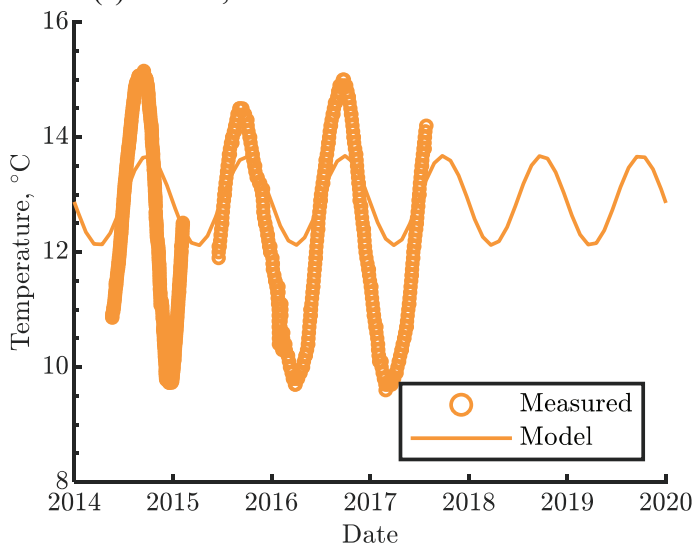

\section{Discussion}

The discrepancies between the modelled and measured temperatures are a consequence of the compounding of uncertainties in the model. Menberg et al. [23] identified a number of critical parameters to which the semi-3D modelling approach has proven to be sensitive. Amongst these are the initial ground temperature; the hydraulic and thermal properties of the geological materials; surface cover types; and density of basements. These uncertainties are unavoidable within the modelling. It is not possible to have full knowledge of initial conditions. Geological properties are difficult to determine and subject to significant spatial variation. The exact heating behaviour of basements will often be unknown and inputs for this will necessarily be based on assumptions. In the face of inevitable uncertainty in model inputs, parameter calibration is necessary to determine the extent of the uncertainty affecting the model outputs. Future work will include using the temperature time series data from up to 60 monitoring boreholes distributed throughout the city of Cardiff to calibrate a larger-scale model of the city, as well as using inverse modelling to quantify the uncertainties associated with various input parameters. Furthermore, the spatially distributed measured data may be used to

(b) CS229, close to basements $z=-7.0 \mathrm{~m}$

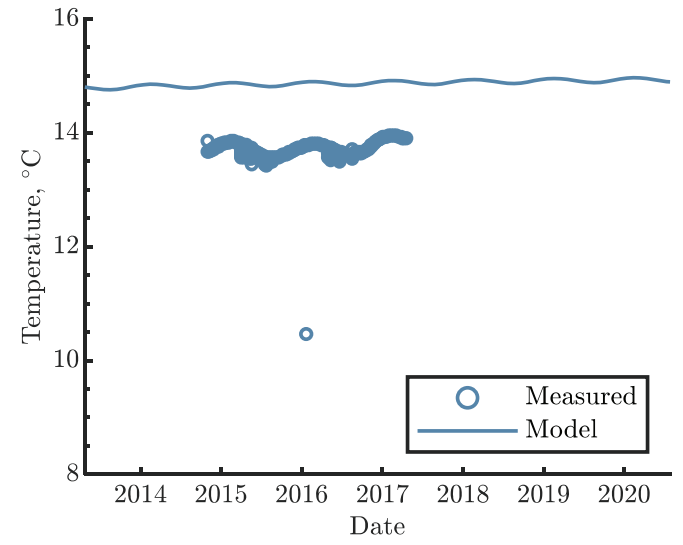

(d) CS283, far from basements $z=-7.7 \mathrm{~m}$

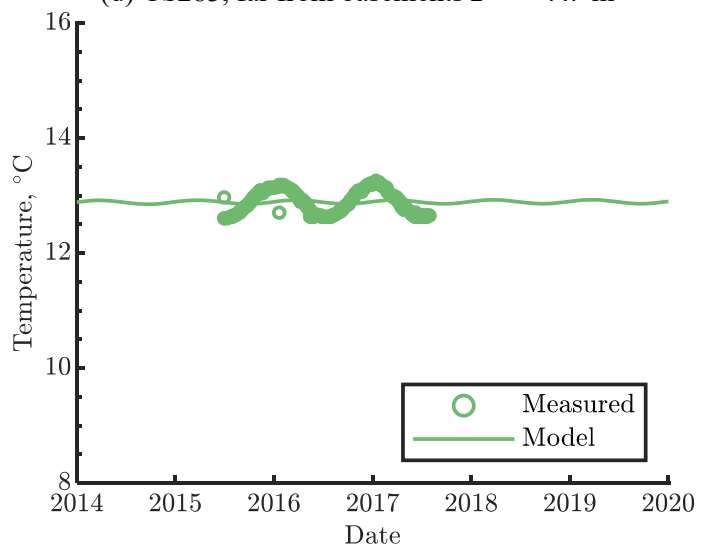

Fig. 7. Measured and modelled temperature time-series at the locations indicated in Figure 6. (a) and (b) show locations near high-density areas of basements, (c) and (d) locations far from basements. 
infer the presence of heat sources and sinks within the shallow subsurface. This will allow the characterisation of measurement locations that are particularly crucial in reducing uncertainty in such models.

The model presented is subject to further limitations. The river in the centre of the domain is not considered in the modelling. Inclusion of this is likely to have an impact on the topmost layers of the model but unlikely to have a great impact at greater depths due to the very low hydraulic conductivity of the geological material immediately below the river. A further limitation is the omission of other heat sources in the ground, such as sewage systems and ground source heat pumps which will likely have a significant effect as the sewage network represents a potentially distributed heat source in the model. Further work would amend the model to incorporate the effects of both phenomena.

\section{References}

1. G. Ferguson, A.D. Woodbury, Subsurface heat flow in an urban environment, J. Geophys. Res.: Solid Earth 109 (2004)

2. A. Bidarmaghz, R. Choudhary, K. Soga, H. Kessler, R.L. Terrington, S. Thorpe, Influence of geology and hydrogeology on heat rejection from residential basements in urban areas, Tunn. Undergr. Space Technol. 92 (2019)

3. J.A. Rivera, P. Blum, P. Bayer, Increased ground temperatures in urban areas: Estimation of the technical geothermal potential, Renewable Energy 103, pp 388-400 (2017)

4. Y. Zhang, K. Soga, R. Choudhary, Shallow geothermal energy application with GSHPs at city scale : study on the City of Westminster, Géotech. Lett. 4:2, pp 125-131 (2014)

5. A. Bidarmaghz, R. Choudhary, K. Soga, H. Kessler, R.L. Terrington, S. Thorpe, Large-scale urban underground hydro-thermal modelling - A case study of the Royal Borough of Kensington and Chelsea, London, Science of the Total Environment 700 (2020)

6. COMSOL Multiphysics ${ }^{\circledR}$ v. 5.5. www.comsol.com. COMSOL AB, Stockholm, Sweden

7. https://www.bgs.ac.uk/products/digitalmaps/digmag b art.html

8. B. Williams, Cardiff Bay barrage: Management of groundwater issues, Proc. I. Civ. Eng. Water Management 161:WM6, pp 313-321 (2008)

9. Ordnance Survey Open Zoomstack. Contains OS data (C) Crown copyright and database right (2019)

10. Verein Deutscher Ingenieure (VDI), Thermische Nutzung des Untergrunds: Grundlagen, Genehmigungen, Umweltaspekte (Thermal use of the underground: Fundamentals, approvals, environmental aspects), VDI 4640. Beuth Verlag GmbH, Berlin (2010)

11. BGS unpublished data, (C) British Geological Survey, UKRI
12. P.R.N. Hobbs, J.R Hallam, A Forster, D.C. Entwisle, L.D. Jones, A.C. Cripps, K.J. Northmore, S.J. Self, J.L Meakin, Engineering geology of British rocks and soils Mudstones of the Mercia Mudstone Group, BGS Research Report RR/01/02, (2020)

13. I.N. Hamdhan, B.G. Clarke, Determination of Thermal Conductivity of Coarse and Fine Sand Soils, Proc. World Geothermal Congress, (2010)

14. D.P. Boon, G.J. Farr, C. Abesser, A.M. Patton, D.R. James, D.I. Schofield, D.G. Tucker, Groundwater heat pump feasibility in shallow urban aquifers: Experience from Cardiff, UK, Science of the Total Environment 697 (2019)

15. B.R. Thomas, Possible effects of rising groundwater levels on a gasworks site: A case study from Cardiff Bay, UK, Quarterly Journal of Engineering Geology and Hydrogeology, 30, pp 79-93 (1997)

16. ENTEC (UK) LTD. Cardiff Bay Barrage Groundwater Control System, Design Modelling Studies. Entec, Shrewsbury, 1997, Report 12206RR290 i3

17. P.J. Armitage, R.H. Worden, D.R. Faulkner, A.R. Butcher, A.A. Espie, Permeability of the Mercia Mudstone: Suitability as caprock to carbon capture and storage sites, Geofluids 16, pp26-42 (2016)

18. G.R. Beardsmore, J.R. Cull. Crustal heat flow: a guide to measurement and modelling, Cambridge University Press (2001)

19. Baggs, S.A., 1983. Remote prediction of ground temperature in Australian soils and mapping its distribution, Solar Energy 30, 351-366

20. G.J. Farr, A.M. Patton, D.P. Boon, D.R. James, B. Williams, D.I. Schofield, Mapping shallow urban groundwater temperatures, a case study from Cardiff, UK, Quarterly J. of Engineering Geology and Hydrogeology, 50:2 pp. 187-198 (2017)

21. Met Office Integrated Data Archive System (MIDAS) Land and Marine Surface Stations Data (1853-current). NCAS British Atmospheric Data Centre (2020)

22. COMSOL Multiphysics ${ }^{\circledR}$ v. 5.5, Heat Transfer Module and Subsurface Flow Module User's Guide [Online]. AC/DC Module User's Guide, pp. 75-84. COMSOL Multiphysics ${ }^{\circledR}$ v. 5.4. COMSOL AB, Stockholm, Sweden. 2018

23. K. Menberg, A. Bidarmaghz, A. Gregory, R. Choudhary, M. Girolami, Multi-fidelity approach to Bayesian parameter estimation in subsurface heat and fluid transport models, Science of the Total Environment, under review 